\title{
Doctor patient relationship: Changing scenario in India
}

\author{
Sourabh Paul', Vikas Bhatia ${ }^{2}$ \\ ${ }^{1}$ Senior Resident, Department of Community \& Family Medicine, All India Institute of Medical Sciences, Bhubaneswar, \\ ${ }^{2}$ Dean, Professor and Head, Department of Community \& Family Medicine, All India Institute of Medical Sciences, \\ Bhubaneswar
}

God has chosen special persons to take care of the physical pains and sufferings of man and such persons are known as doctors. But recently countrywide dissatisfaction on the major pillar of the medical services raises number of questions. In this present article authors have tried to find out the related factors with the changing scenario of doctor- patients relationship from India's prospective. In the ancient India, doctors were enjoying the highest level of respect in the society because of the attitude and activity towards the patient. In the last decade of the $20^{\text {th }}$ century and beginning of $21^{\text {st }}$ century, a chronic dissatisfaction began to settle over the relationships between doctors and patients. High level of corruption in the health care industry, inequity in health care delivery, technological development in medical science, growth of health insurance, patient's desire in share decision making, information technology development are few factors behind changing doctor- patient relationship. If physicians take a little more time in reassuring patients in the old fashioned way, this will restore the deteriorating relationship.

Key words: Doctor patient relationship, Medicine in India, Patient satisfaction
http://nepjol.info/index.php/AJMS DOI: 10.3126/ajms.v7i4.13929 E-ISSN: 2091-0576 P-ISSN: 2467-9100

\section{INTRODUCTION}

Human beings are the noblest creation of God on the surface of the earth but life span of them are predetermined and pain and pleasure are part and parcel of life. Doctors are such special persons who take care of the physical pain and suffering of human beings. So, they were truly termed as next to the God. ${ }^{1}$ Medicine is the most scientific of humanities and it is a discipline combining science with art. $^{2}$ The ancient Indian physician Charaka once said, "A good physician nurtures affection for his patients exactly like a mother, father or brother. The physician having such qualities gives life to the patients and cures their diseases." The doctor-patient relationship has long been assumed to be a straight forward association between an expert in medicine and a person in need of medical care. ${ }^{3}$ The building stone of any successful relationship is element of trust and it is utmost important in case of doctor patient relationship. A vulnerable patient always trust a physician to recover soon. ${ }^{4}$ Patients have clinical care needs as well as interpersonal care needs.Clinical care requires skills of diagnosing and treating. Interpersonal care requires qualities of integrity, honesty, respect, empathy, compassion and altruism. ${ }^{5,6}$ Emanuel and Dubler have suggested that the ideal doctor-patient relationship consists of the six C's: Choice, competence, communication, compassion, continuity, and (no) conflict of interest. ${ }^{7}$ The relationship between doctors and their patients is the topic of warm discussion since the time of Hippocrates and received place in more than 8,000 available medical literatures. ${ }^{8,9}$ In past, there was no question about this noble service but recently countrywide dissatisfaction on the major pillar (doctors) of the medical services raises number of questions. In the last few decades, rapid changes in the health care delivery system in India have resulted in considerable strain on this relationship. Ironically, the changes of the relationship have led to increased recognition of the relationship's deeper dimension as an intimate interaction between two human beings in issues of health, illness and sometimes death. ${ }^{3}$ A robust science of the doctor- patient encounter 
and relationship can guide decision making in health care plans. ${ }^{8,9}$ In this present article authors have tried to find out the related factors with the changing scenario of doctor- patients relationship from India's prospective.

\section{ORIGIN OF MEDICINE IN INDIA}

The era of medicine in India can be divided into the following timeline: i) Ancient Indian medicine (ii) Indian medicine in medieval times (iii) Indian medicine during the nineteenth century and the first half of the twentieth century (iv) Progress after Independence (v) Last part of twenty century and $1^{\text {st }}$ part of twenty first century. ${ }^{10}$ (i Ancient Indian medicine: The medical history of ancient India was authenticated mainly in the writings of the two great sages of Indian medicine-Sushruta, the surgeon and Charaka, the physician. ${ }^{10,11}$ ii) Indian medicine in medieval times: In this era there was a great set back in the history of Indian medicine because Muslim continued to practice their own system of medicine in India. (iii) Indian medicine during the nineteenth century and the first half of the twentieth century: Western medicine introduction in India started in the $1^{\text {st }}$ part of nineteenth century when British started ruling India and that was the introduction of modern system of medicine in India. Quarantine Act 1825, Vaccination Act 1880, epidemic disease act 1897 shows the public health movement in India. ${ }^{12,13}$ (iv) Progress after Independence: In the last half of twentieth century progress in health care system was imminence and multidirectional. Number of health institute starting from service delivery institute to medical colleges has increased. Doctor population ratio, doctor nurse ratio also started improving. Family physician/MBBS doctor (having proper knowledge of medicine) was the backbone for delivering health services in the rural India. Contributory health scheme was also introduced during this era. ${ }^{14,15}$ (v) Last part of twenty century and $1^{\text {st }}$ part of twenty first century: India has seen rapid development in medical care scenario. Private organization has increased their involvement both in healthcare delivery as well as medical education. Excellent development has occurred in the laboratory technology \& diagnostic services. Specialist and super specialist have started dominating India's health care market.

\section{DOCTOR PATIENT RELATIONSHIP IN THE PAST}

In the ancient India, doctors were enjoying the highest level of respect in the society because of the attitude and activity towards the patient. They were labelled as next to God. In that era medicine practice was seen from social and humanitarian point of view rather than taking it as a business point of view. In the early and middle part of twentieth century maximum doctors in India were general physician or family physician. Maximum of these doctors were practicing in rural area and there were hardly few specialist who were only available in large urban area. These general physicians usually practiced medicine in their own village or nearby area. So they developed a good relationship with the community because they were always available round the clock and they usually discussed with the patients regarding different matters of family rather than usual doctor- patient communication. They usually knew the health status of all family members of the patient. As a result a good interpersonal relationship was developed between doctor and patient. These family physicians explained to their patients nicely the problems, probable diagnosis, treatment protocol and patient also were able to express their views as much as possible because there was no time constrain in the consultation process. In this process patient developed a trust on the physician. Patient hardly believed that doctor could do any harm to the patient or if sometimes any unwanted condition aroused then patient thought that it was only God's will. These general physicians only referred the genuine cases to the specialist and the cost for consultation was very minimal sometimes the poor patients offered some fruits, paddy or vegetables to them. Patient and doctor both were benefited from this type of relationship and finally society had strong trust on the doctors.

\section{MODERN INDIA DOCTOR PATIENT RELATIONSHIP}

In the last decade of the $20^{\text {th }}$ century and beginning of $21^{\text {st }}$ century, a chronic dissatisfaction began to settle over the relationships between doctors and patients. People were doing better but feeling worse. As the medical science is progressing the personal, strong and trusting relationship is deteriorating.

Few example of modern doctor patient deteriorating relationship in India

1. A patient was brought to the emergency department of AIIMS, Delhi on July14, 2014 evening. A senior resident doctor examined the case and found that it was a case of neurosurgery, so he called for a neurosurgeon. While waiting for the neurosurgeon the patient's relative became restless and started a ruckus. Later on doctors went for strike for few hours in protest of the incident. ${ }^{16}$

2. A politician from Uttarpradesh one fine evening of $28^{\text {th }}$ February 2014 attacked the doctors of Kanpur's Halet Hospital for mistreating a patient. The incident took a bigger look when many doctors of the government hospital went on strike following the incidence. Later on Supreme Court had to interfere into the incidence. ${ }^{17}$ 
3. A female patient was admitted in the Malda medical college hospital and she was declared dead on $18^{\text {th }}$ August 2014. Next morning when the patient relatives went to take her body she was moving her hand and feet, which produced a great hue and cry in the hospital. Finally medical superintendent ordered an inquiry against the accused doctor. ${ }^{18}$

4. A child psychologist visited AMRI, hospital Kolkata with skin rashes on April 25, 1998. She was treated by three physicians and later on $28^{\text {th }}$ May, 1998 she died from a very rare type of skin cancer, "Toxic epidermal necrolysis". On 24 $4^{\text {th }}$ October 2014 Supreme Court has given a verdict to compensate 5.96 cores by three doctors and AMRI hospital to the victim's husband. ${ }^{19}$

5. A patient of stomach ache went to 'Adarsh polyclinic \& laboratory' in Mumbai for HCV antigen test on $6^{\text {th }}$ August of 2007. Later on he came to know that the test was done on 'Metropolis clinic' and gave a wrong report of $\mathrm{HCV}$ reactive. District consumer forum has directed both the laboratory to compensate him 11,675 for error in diagnosis along with 15,000 with interest for mental agony caused due to wrong diagnosis. ${ }^{20}$

6. Probable factors behind this deteriorating doctor patient relationship:

1. High level of corruption in the health care industry: Corruption is the biggest enemy of present India. It has touched every level of the society and unfortunately it has not bypassed the health care industry also. Corruption exists both in the government as well as private health care system which is gradually destroying the doctorpatient relationship. Doctors are prescribing costly and unnecessary medicines and laboratory tests for financial commission, foreign tour and costly gifts. Private hospitals are keeping patients unnecessarily in the I.C.U for extra charge. Good number of scams in NRHM is destroying the reputation of doctors. In last few decades there has been a tremendous involvement of the private sector in medical education system (establishment of medical college, nursing, and pharmacy colleges). Students have to pay very large "donations" (perhaps $\$ 200000$ or more, some 20 times the average doctor's annual salary) to get into the rapidly increasing number of private medical colleges and to get on to sought after postgraduate training schemes. ${ }^{21}$ This will produce a great impact on the attitude of the doctor when he starts practicing medicine. Doctors start working for multiple hospitals or gets into the game of commission with pharmaceutical companies to regain their investment. It is the extra hunger for money among the doctors is behind the deteriorating doctor- patient relationship.
2. Inequity in health care delivery: Health care delivery system still in modern India is a model of inequity. Though equity in health care delivery is the goal of India government still a vast inequity exist in health care system. Those who can pay are able to enjoy highest level of health care while majority of the poor and middle class have to depend on government health care system. Public health care system in India is suffering from deficient manpower, infrastructure, modern advanced technology, unmanageable patient load etc. ${ }^{22}$ Coronary Artery Bypass Grafting (CABG) is one of the lives saving procedure for myocardial infarction patient. Cost of CABG in private hospital is between $\$ 6600-\$ 9,800 .^{23} \mathrm{~A}$ patient from high economic condition can afford this price whereas those from lower socio- economic condition have to depend on public health care facility. As a result the ultimate fate of the patient of two different backgrounds will be different. Because of this inequity in health care delivery system all the anger and frustration of the poor patient and their relatives go against the doctors (easily accessible) and they become hostile and violent.

3. Technological development in medical science: Medical technology has made remarkable advancement in the last few decades. CT scan, MRI, Ultrasound, laparoscopic surgery, endoscopy, biopsy etc has made diagnosis easier. One side of this advancement in technology is resulting in better clinical outcomes, less invasive procedures and shorter recovery times and thus improving overall health of people. But on other side patients and their relatives perceiving that advancement in medicine will surely save life of the dearest. Early and accurate detection doesn't mean 100\% surety of saving patient's life. So when there is a difference between the expectation of the patient's relative and ground reality, it outbursts in the form of violence. ${ }^{24}$

4. Inadequate doctor patient ratio: Sixty years ago in India the total number of physicians was 47,524 , with doctor population ratio of 1 to 63007.Today the number of registered medical practitioners is 840,130 (a 17-fold increase). Despite the population explosion (population has tripled) the overall doctor population ratio is now 1:1800 which reflects a 3.5 fold improvement. ${ }^{25}$ Still India's doctor population ration is less than the WHO recommendation of 1:1000. Because of this disproportionate doctor- population ratio doctor is not able to spend much time during consultation process (especially in urban setting). So most of 
the time patients are not satisfied, as a result the relationship is deteriorating day by day.

5. Expanding middle class population and growth of health insurance: There is rapid expansion of the middle class population in India, from 25 million people in 1996 to 153 million people in 2010. The middle class population was rapidly acquiring the purchasing power necessary to afford quality western medicine due to an increase in disposable income. The Indian population spent $7 \%$ of its disposable income on healthcare in 2005; $14 \%$ in 2009-10 and this number was expecting to nearly double by $2014-15 .{ }^{26}$ In the last few decades there has been a phenomenal expansion of different form of health insurance both in government and private sectors. With these trends people are ready to pay even higher amount for saving lives of their beloved. In return they are expecting best possible services (i.e. high probability of survival of the patients). Poor services or any type of negligence flare-ups the emotion of patients and relatives.

6. Patient's desire to become a part in the decision making process: Traditionally the ideal doctorpatient relationship was paternalistic; doctors direct care and makes decisions about treatment. During the past few decades, patients and their relatives wants shared decision making. ${ }^{27-29}$ Many of the time it has been found that correct informed consent have not taken before costly investigation or invasive procedure. Smith et al have found that higher levels of information- giving by the doctor, the time spent in discussion of preventive care by the doctor and grater interview length were positively associated with patient satisfaction. ${ }^{30}$ Unfortunately nowadays most of the doctors because of their busy schedule have forgotten this important area of communication.

7. Expansion of literacy and awareness of Consumer protection Act 1986: When Literacy rate was very less, whatever told and asked by the doctors was the final word for patient. Patient had "blind faith". But as the literacy rate increased [Figure 1] patient and their relatives were asking questions on doctor's unrealistic behaviour as a result the relationship was deteriorating. Patient and their relatives are now more aware regarding their rights and one of greatest weapon in their hand is the Consumer protection act 1986. Today number of negligence cases against doctors in Consumer protection court is increasing rapidly as a result the relationship of understanding is deteriorating. ${ }^{31}$

8. Easy accessibility to information: Most of the $20^{\text {th }}$ Century due to lack of information patient had the thinking that "Doctor Knows the best".
However, coming to the information age patients are empowered with information. "Blind trust is being replaced by “informed trust". Williamson's et al conducted a study in 1997, showed that $98 \%$ of the respondents offer the view that doctors as well as other health professionals were the most authoritative and used sources of health information. ${ }^{32}$ Recently conducted study by RAND Corporation 2005, found that among those looking for information about health, $69 \%$ mentioned the internet as a source, compared to $59 \%$ who mentioned their own physicians, and $39 \%$ who cited other health care professional [Table 1]. ${ }^{33}$

In India last 15 yrs there has been 162 times increase in the rate of internet access. As a result, patients have a wide range of knowledge related with medical condition through internet which once upon a time was only considered doctor's area of interest. Doctors think that these well informed patients are either over smart or problematic.

\section{CONCLUSION}

The doctor patient relationship has changed massively in the last few decades in our country. The doctors of the past were treated like God. Today there is rapid commercialization and globalization on all spheres of life and the medical profession is no exception to these phenomena. To improve this scenario both doctors and

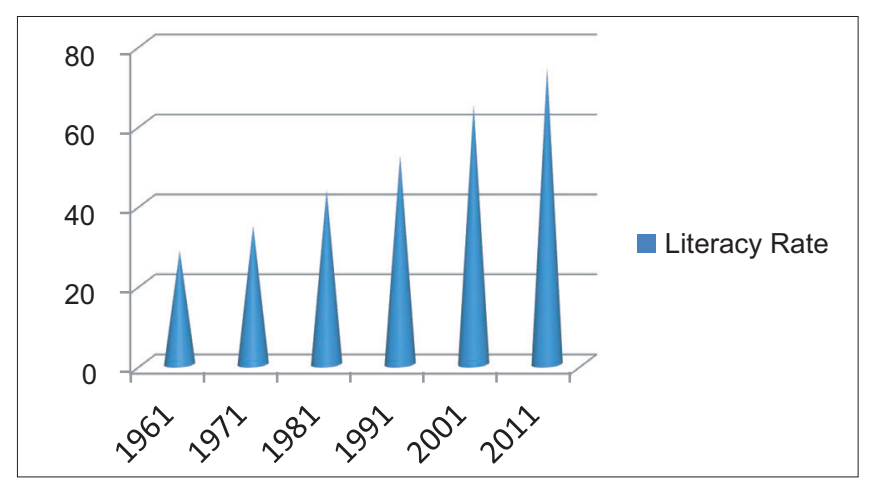

Figure 1: Literacy rate of India after independence ${ }^{31}$

\begin{tabular}{lcc} 
Table 1: Internet users proportion in India & \\
\hline Year & $\begin{array}{c}\text { Inter users } \\
\text { (million) }\end{array}$ & $\begin{array}{c}\text { Proportion with } \\
\text { population of India }\end{array}$ \\
\hline 1998 & 1.4 & 0.1 \\
2000 & 5.5 & 0.5 \\
2002 & 16.5 & 1.6 \\
2004 & 39.2 & 3.6 \\
2006 & 40.0 & 3.6 \\
2010 & 100.0 & 8.5 \\
2012 & 137.0 & 11.4 \\
2013 & 205.0 & 16.2 \\
\hline
\end{tabular}


patients personally should retrospect either behaviour. Professional bodies, patients and social activist should debate and find out the solutions. Most of the doctorpatient conflicts can be resolved with a fair discussion and proper communication. Doctors besides a treating physician; has to remember the sociology, psychology of the patient and his relatives. If physicians take a little more time in talking, in reassuring patients in the old fashioned way, this will restore the deteriorating patient physicianrelationship.

\section{REFERENCES}

1. Jaiswal A and Bahatnagar AS. Doctor-patient relationship: A Socio-legal Analysis. Shodh Sanchayan 2013;4 (1):1-8.

2. Hodgson $\mathrm{K}$ and Thomson $\mathrm{R}$. What do medical students read and why? A survey of medical students in Newcastle-upon-Tyne, England. Medical Education 2000; 34: 622-629.

3. Shelton SB. The doctor-patient relationship. In: Stoudemire A, editor. Human behaviour: an introduction for medical students. Philadelphia: Lippincott-Raven, 1998; 3-35.

4. Pellegrino ED and Thomasma DC. The virtues in medical practice. New York: Oxford University Press 1993.

5. Campbell SM, Roland MO and Buetow SA. Defining quality of care. Social Science and Medicine 2000; 51: 1611-1625.

6. Siegler M. Caplan A and Singer P. Clinical medicine, clinical ethics and physician's professionalism. In: HD Hurries eds. Kelley's Textbook of Internal Medicine. $4^{\text {th }}$ ed. Philadelphia: Lippincott Williams \& Wilkins, 2000.

7. Emanuel EJ and Dubler NN. Preserving the physician patient relationship in the era of managed care. JAMA 1995; 273:323-329.

8. Gordon GH and Rost K. Evaluating a faculty development course on medical interviewing. In: Lipkin M Jr, Putnam SM, Lazare A, eds. The Medical Interview: Clinical Care, Education, and Research. New York, NY: Springer-Verlag, 1995,pp 248-253.

9. Levinson $W$ and Roter $D$. The effects of two continuing medical education programs on communication skills of practicing primary care physicians. J Gen Intern Med 1993;8: 318-324.

10. Annual Reports, Ministry of Health, Government of India,[Online] 1947-1965 [cited 2015 May 26]. Available from: http://www. mohfw. nic. in/index1.php?lang=1\&level=2\&sublinkid=5253\&l $\mathrm{id}=3215$.

11. Crawford DG. History of the Indian Medical Service, 1600-1913. $2^{\text {nd }}$ vol., London: W. Thacker; 1914.

12. Dwarakanth C. Indian Systems of Medicine (origin and development). Swasth Hind, Souvenier of the $14^{\text {th }}$ World Medical Association Congress. 1961:257-264.

13. Kutumbiah P. Ancient Indian Anatomy. In: Ancient Indian medicine. Madras: Orient longman, 1962, p 1-32.

14. Tra M and Jivru N. 'Health problems of the Indian Union'. Ind J Med Sci 1948; 2(4).
15. Vakil RJ. Our Glorious Heritage, Bombay: Times of India Press; 1966.

16. Patient's kin pull out guns, beat up three doctors at AllMs emergency. The Indian Express. 2014 July 15;Sec cities.

17. Samajwadi party lawmaker Irfan solanki booked for attack on doctors. Press trust of India. 2014 March7; Sec cities.

18. Patient declared dead by doctor, found alive by family members. The Times of India. 2014 Aug 19; Sec cities.

19. Kolkata hospital, 3 doctors told to pay Rs. $5.96 \mathrm{Cr}$ for negligence. The Times of india. 2014 Oct 24; Sec India.

20. Private lab told to compensate patient for giving wrong reports. Daily news \& Analysis. 2012 Mar 5; Sec news (Mumbai).

21. Berger D. Corruption ruins the doctor-patient relationship in India. BMJ 2014; 348: 3169.

22. Bajpal V. The challenges confronting public hospitals in India, Their origins and possible solutions. Advances in Public Health 2014:24;1-27.

23. Health Tourism.com. CABG (Coronary Artery Bypass Graft) in Chennai. [Online] 2008 [cited 2014 August 15]. Available from: http://www.health-tourism.com/coronary-artery-bypass-graft/ india-c-chennai/\#Cost.

24. Divekar $S$ and Sukhadeve V. Doctor-patient relationship worsening in India context. IJARS 2017; 1(2): 1-9.

25. Deo GM. Doctor population ratio for India- The reality. Indian J Med Res 2013;137: 632-635.

26. Annual Report to the people on Health. Government of India, Ministry of Health and Family Welfare [online] 2010 [cited 2015 March 17]. Available from: http://mohfw.nic.in/ WriteReadData/l892s/6960144509Annual\%20Report\%20 to $\% 20^{\text {th }}$ \% 20 People $\% 20$ on $\% 20$ Health.pdf.

27. Chaitchik S, Kreitler S, Shaked S, Schwartz I and Rosin R. Doctor-patient communication in a cancer ward. J Cancer Educ 1992; 7(41).

28. Becisecker A and Beiscker TD. Patient information-seeking behaviors when communicating with doctors. Med Care 1990; 28.

29. Sutherland H J, Llewellyn-Thomas HA and Lockwood GA. Cancer patients: their desire for information and participation in treatment decisions. J R Soc Med 1986; 260(82).

30. Smith C K, Polis E and Hadac R. Characteristics of the initial medical interview associated with patient satisfaction and understanding. J Family Practice 1982;12:283.

31. Number of literates and Literacy rate of India. Census of India [online] 2010-11[cited 2014 August13]. Available from: http:// indiabudget.nic.in/es2001-02/chapt2002/chap106.pdf.

32. Reents S. Impacts of the internet on the doctor-patient relationship: the rise of the internet health consumer. New York: Cyber Dialogue: 1999.

33. Crisil Research Hospitals Annual Review [online] November 2010 [cited 2015 June 15]. Available from: http://www.crisil. $\mathrm{com} / \mathrm{pdf} /$ research/research-industry-information-report-hospitalcontents.pdf.

34. Internet usage stats and telecommunications market report. Internet World Stats [online] 2001-2014 [cited 2015 August 5]. Available from: http://www.internetworldstats. com/asia/in.htm. 